\title{
Simulation Research of Aircraft Piston Engine Rotax 912
}

\author{
Lukasz Grabowski ${ }^{1, *}$, Ksenia Siadkowska ${ }^{1}$, and Krzysztof Skiba ${ }^{1}$ \\ ${ }^{1}$ Lublin University of Technology, Faculty of Mechanical Engineering, Department of Thermodynamics, Fluid Mechanics and \\ Aviation Propulsion Systems, Nadbystrzycka 36 Str., 20-618 Lublin, Poland
}

\begin{abstract}
This paper reports the results of simulation works of Rotax 912 aircraft piston engine, which is a basic unit in most ultra-light aircrafts. The method for preparing the model aircraft engine operation process was presented. Simulation tests were carried out in the AVL Boost programme. The programme allows a full use of zero-dimensional and one-dimensional modelling. It also allows a comparison of other engine models. The developed model has enabled us to simulate the flow of air through the inlet pipes, carburettors, valves and combustion process. The preparation of the model required us to enter parameters that are not available in the manufacturer's catalogue, therefore, necessary measurements and analysis of the engine parts were carried out on a laboratory bench. The calculations in the AVL Boost programme were carried out in the conditions determined for the selected BMEP values with the objective of characterising the engine performance by determining its power, torque and fuel consumption.
\end{abstract}

\section{Introduction}

Piston internal combustion engines are still used to drive light aircrafts. This is mainly related to lowering the specific fuel consumption [1,2]. An example of a popular piston engine is Rotax 912, which is used mainly in light aviation. According to [3], 40,000 units were sold, 25,000 of which are still in use, and $88 \%$ of all light aircraft OEMs use Rotax engines. Rotax 912 engines are considerably popular in Europe and in the United States as they do not require AVGAS fuel, ensure less fuel consumption than competing engines, e.g. Continental O-200 and long TBO, even up to 2000 hours; depending on an engine series. The popularity of the research object is illustrated with the Google AdWords tool in Fig. 1 that shows the average monthly number of searches for given engines from a given segment. The selected options are: all locations, all languages, Google, display only closely related suggestions.

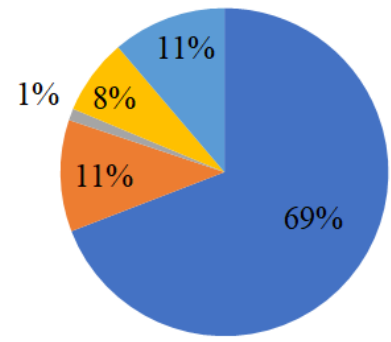

$\operatorname{rotax} 912$

- $\operatorname{rotax} 914$

lycoming 233

lycoming 235

continental 200

Fig. 1. The popularity of the research object in the indicated market segment.

In the research identifying key entities in the engine industry [4], the then FA Bombardier Rotax was indicated as one of the companies active in engine research and development. Numerous tests are carried out using Rotax engines [5-8]. In NASA's The Green Flight Challenge programme, aimed at developing technology and increasing aviation efficiency, one of the teams used the Rotax 912 engine in its EcoEagle aircraft [9].

The paper [10] presents simulation tests of a cooling system in a gyro concept powered by two Rotax $912 \mathrm{~S}$ engines. The authors [11, 12] studied the knock phenomenon in the Rotax 914 engine. In the article [13], the one-cylinder four-valve Rotax engine was modified and CFD mixture analysis was performed using Large-Eddy Simulation. The authors of the article [14] focused on the optimisation of combustion in the 4-stroke Rotax engine to reduce emissions.

Computational Fluid Dynamics simulations are commonly used to model the flow and combustion processes in internal combustion engines [15-18]. These processes, however, require long calculation time to analyse engine performance. Therefore, 1D modelling is widely used $[19,20]$. The authors of the work [21] used the 1D model together with phenomenological submodels to describe the phenomena occurring in the cylinder and to validate them with experimental results. A 1-D multi-step global kinetic Selective Catalytic Reduction model was used to analyse methods for reducing NOx emissions [22].

$0 \mathrm{D} / 1 \mathrm{D}$ modelling compared to the results of $3 \mathrm{D}$ simulation was used in [23] for optimisation of the performance of a two-stroke Diesel engine for aircraft propulsion. In work [24], a zero-dimensional model of an aircraft engine was used to analyse the

\footnotetext{
* Corresponding author: 1.grabowski@pollub.pl
} 
performance of the engine depending on the selected parameters of the mechanical compressor. In another work [25], authors investigate the thermodynamic model of the ASz-62IR radial aircraft engine. The authors of the works [26, 27] defined the methodology of an effective optimisation of the combustion engine and the fuel injector construction by means of 1D fluid dynamic simulation models. The paper [28] investigates toxic emissions emitted by aircraft radial engine under flight using the $1 \mathrm{D}$ model. The authors of [28] present CFD cooling model of the air-cooled aircraft engine, the boundary conditions for which were derived from the 1D model.

Our study involved developing a model of Rotax 912 ULS and subjecting it to simulation tests, carried out by means of the AVL Boost software.

\section{Problem description and objective}

The article presents the method of mapping the model aircraft operation process of the Rotax 912 engine. This engine is a basic unit in most ultra-light aircrafts. The numerical model was created for the Rotax 912 ULS gasoline engine. It has a maximum power of $73.5 \mathrm{~kW}(100 \mathrm{hp})$ obtained from a capacity of $1352 \mathrm{~cm}^{3}$. The drive unit consists of a four-stroke piston engine with an integrated reduction gear located in the engine body, which allows the propeller to be directly mounted on the drive hub. The engine has four air-cooled cylinders in a boxer system and liquid-cooled cylinder heads. It is also equipped with a lubrication system with the so-called dry oil pan. The fuel mixture is given by two independent carburettors of constant vacuum, preceded by air boxes. The ignition is a dual system with four coils and two electronic modules.

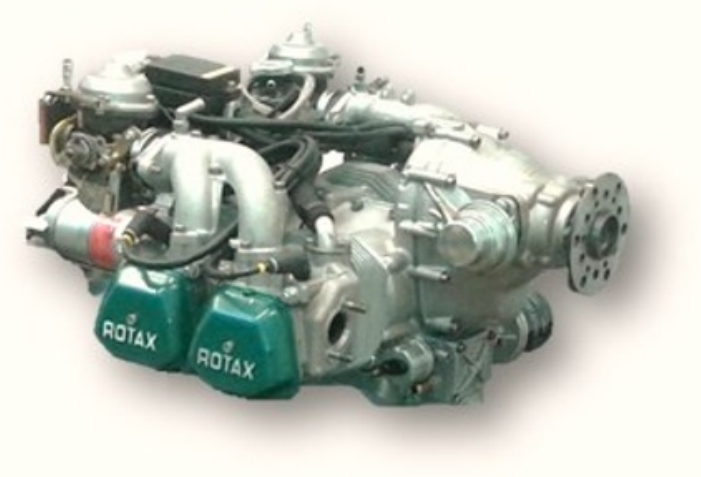

Fig. 2. Rotax 912 ULS.

\section{Methods}

Simulation tests were carried out in the AVL Boost programme. This programme is fully integrated software for simulating engine operation. It enables creation of advanced models that allow you to predict the engine performance and emissions as well as the reproduction of cylinder operation parameters. The programme enables a full use of zero-dimensional and one-dimensional modelling. It also enables a comparison of other engine models.
The AVL Boost software is capable of preparing a virtual engine model for simulation tests. Thanks to the extended interface, it helps to develop a drive unit built of real components. However, an in-depth analysis of both the design and phenomena occurring during engine operation are required. Creating a model based on only catalogue data is a complicated process because numerous values and coefficients need to be specified in real object measurements and mathematical analyses.

The developed Rotax 912 ULS engine model is a one-dimensional model. Ducts connecting individual cylinders with other elements of the model are of specific lengths and diameters. The diagram below (Fig. 3) shows the Rotax 912 ULS engine as a 1D model created in the AVL Boost programme. Table 1 lists individual elements of the model.

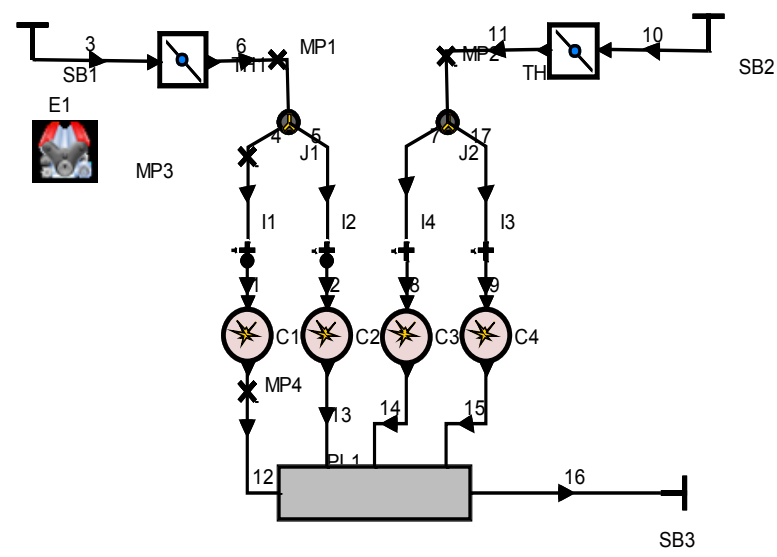

Fig. 3. Rotax 912 ULS engine model in AVL Boost.

Table 1. Elements of the Rotax 912 ULS engine model in AVL Boost.

\begin{tabular}{|l|c|}
\hline \multicolumn{1}{|c|}{ Element } & Symbol \\
\hline Engine & $\mathrm{E}$ \\
\hline System Boundary & $\mathrm{SB}$ \\
\hline Pipe & - \\
\hline Junction & $\mathrm{J}$ \\
\hline Throttle & $\mathrm{TH}$ \\
\hline Injector & $\mathrm{I}$ \\
\hline Cylinder & $\mathrm{C}$ \\
\hline Measuring Point & $\mathrm{MP}$ \\
\hline Plenum & $\mathrm{PL}$ \\
\hline
\end{tabular}

The developed model was implemented to simulate the flow of air through the inlet pipes and then through two carburettors. The carburettors were simulated using two throttles (Throttle modules) and four injectors as the Injector Nozzle model working in a continuous fuel injection mode (Continuous Injection). The duct coming out of the carburettors representing intake manifolds were connected to the cylinders in which the fuel mixture is burnt and combustion products are discharged through the 
exhaust pipe assembly outside the engine. The measuring points in the engine model were located in different parts of the engine, e.g. behind the throttle or at the exhaust outlet of the cylinder.

The initial conditions necessary to carry out the calculations were introduced in the Simulation Control. The initial pressure was 1 bar and the air temperature was $25^{\circ} \mathrm{C}$. The fuel is unleaded petrol with $95 \mathrm{RON}$ whose calorific value is $43.5 \mathrm{MJ} / \mathrm{kg}$. The simulation tests were carried out during 250 working cycles. In the model above, the cylinders were modelled in accordance with the manufacturer's factory data presented in Table 2 . All cylinders have the same parameters so the Identical Cylinders rule was used to parameterise the remaining three cylinders.

Table 2. Technical data of the Rotax 912 ULS.

\begin{tabular}{|l|l|}
\hline Cylinder bore & $84 \mathrm{~mm}$ \\
\hline Stroke & $61 \mathrm{~mm}$ \\
\hline Displacement & $1352 \mathrm{~cm}^{3}$ \\
\hline Compression ratio & $10.8: 1$ \\
\hline
\end{tabular}

The preparation of the model required us to enter parameters that are not available in the manufacturer's catalogue so certain measurements and analysis of the engine parts were carried out on a laboratory bench. This method determines, e.g. the length of the connecting rod, the value of the lift of the inlet and outlet valves as a function of the cam rotation angle. The course of the curves is shown in Figure 4.

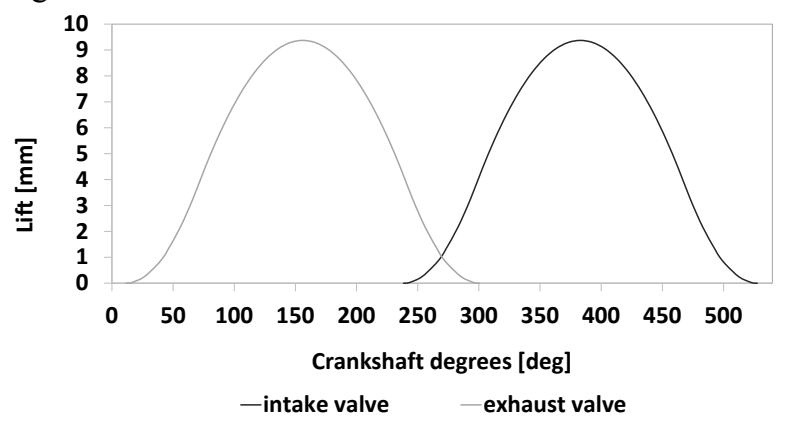

Fig. 4. Intake and exhaust valve lifts vs. the cam rotation angle.

The measurements and the analysis of the camshaft timing enabled us to specify the angular opening values of the valves as a function of the crankshaft rotation for individual cylinders.

The model also includes frictional phenomena occurring in the engine. The applied Engine Friction Table function determines the FMEP characteristics, or the average effective pressure resulting from friction. The course of the FMEP characteristic curve as a function of rotational speed was determined empirically, and the results are presented in the graph below (Fig. 5).

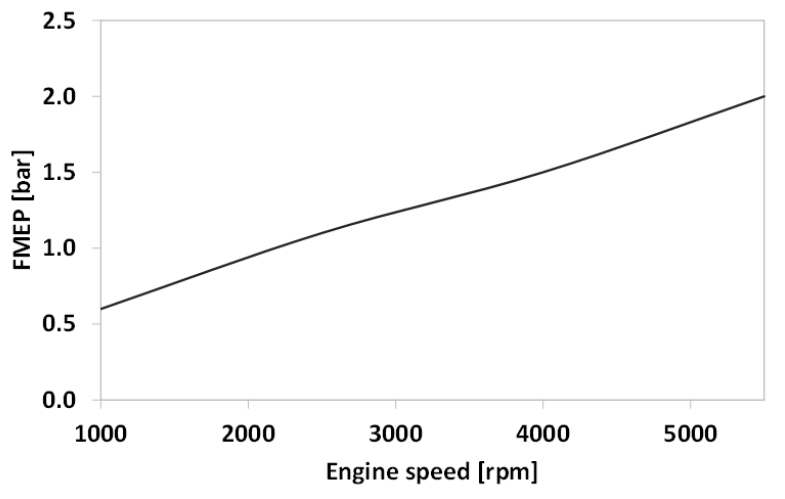

Fig. 5. FMEP vs engine speed.

The scope of our engine tests included the calculation of the engine's effective power in the selected crankshaft rotational speeds. During our calculations, the BMEP values were entered into the columns in the Case Explorer dialogue box. The characteristic values of engine working points and maximum MAP values are given in the manufacturer's chart (Fig. 6) [30].

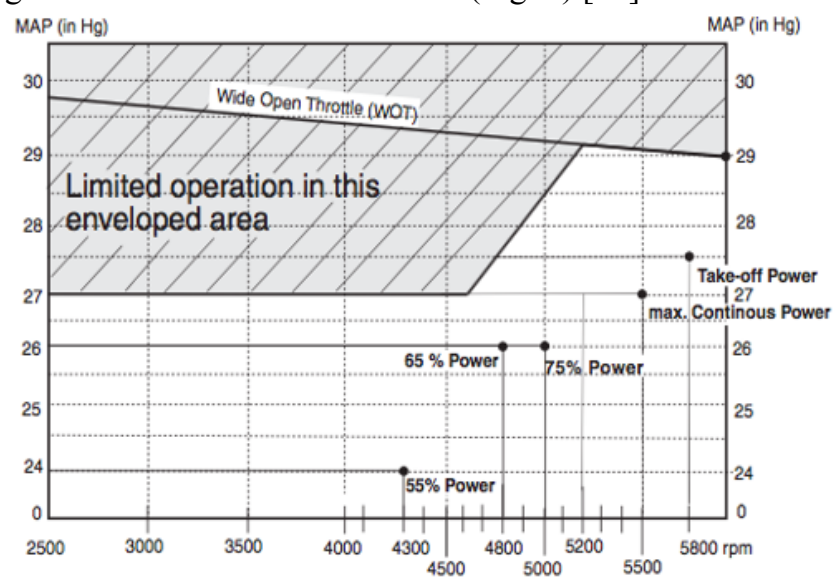

Fig. 6. MAP [30]

The values from Fig. 6 provided data for the calculation of the engine performance, i.e. power and torque. In order to determine the engine's operating conditions, calculations for 250 cycles were made. The model was calibrated for each of the engine speeds. In order to obtain the expected engine power, the AFR and the average effective pressure resulting from friction in the Engine E1 module were calibrated.

The calculations in the AVL Boost programme were carried out in the conditions determined for the selected BMEP values derived from formula (1), based on the characteristics of the engine torque power as a function of the rotational speed specified by the manufacturer. The calculated values are shown in Table 3 . For each operating point, the amount of mixture in the cylinder was selected to obtain the required BMEP value. Mass air flow through the engine was defined by changing the throttle opening angle.

$$
B M E P=\frac{W_{n}}{V_{d}}=\frac{2 \pi * T * n_{g}}{V_{d}}->T=\frac{B M E P * V_{d}}{2 \pi * n_{g}}
$$


where:

$\mathrm{T}-$ torque $[\mathrm{Nm}]$

$\mathrm{n}_{\mathrm{g}}=2$, (for a 4-stroke engine)

$\mathrm{V}_{\mathrm{d}}$ - engine displacement

Table 3. BMEP.

\begin{tabular}{|c|c|c|}
\hline $\begin{array}{c}\text { Engine speed } \\
{[\mathrm{rpm}]}\end{array}$ & $\begin{array}{c}\text { Engine torque } \\
{[\mathrm{Nm}]}\end{array}$ & $\begin{array}{c}\text { BMEP } \\
{[\mathrm{bar}]}\end{array}$ \\
\hline 3000 & 101.75 & 9.46 \\
\hline 3500 & 114.60 & 10.65 \\
\hline 4000 & 119.40 & 11.10 \\
\hline 4500 & 126.25 & 11.73 \\
\hline 5000 & 128.00 & 11.90 \\
\hline 5500 & 124.00 & 11.53 \\
\hline
\end{tabular}

\section{Results and Conclusion}

This chapter compares the results obtained from the simulation with the figures derived from manufacturer catalogue. Figure 7 shows the characteristics of engine power as a function of rotational speed in the range $3000-5800 \mathrm{rpm}$. The power calculated by the AVL Boost programme is slightly different from the values given by the manufacturer. Initially, for speeds of $3000 \mathrm{rpm}$, it is higher by $0.92 \mathrm{~kW}$ in relation to the catalogue value. As the speed increases, the engine performance increases, but in the 3500-5000 rpm range, the power is $1.58-2.56$ $\mathrm{kW}$ lower than the one specified by the manufacturer. Above $5000 \mathrm{rpm}$, the power in simulations rises above the declared by the manufacturer and reaches a maximum value of $76.91 \mathrm{~kW}$. The highest overestimation of the computer model with respect to the real one occurs at $5800 \mathrm{rpm}$ and then the engine performances differ by $3.41 \mathrm{~kW}$.

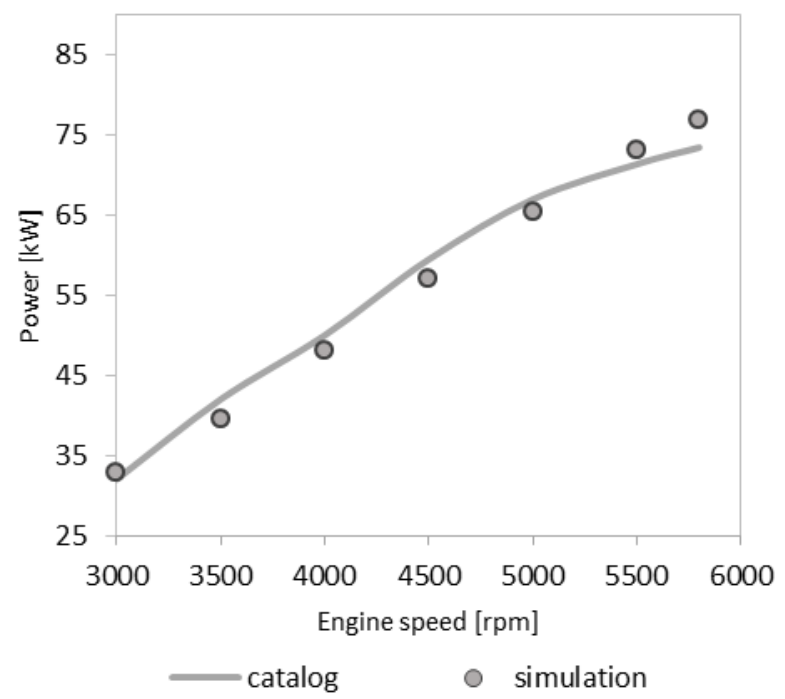

Fig. 7. Rotax 912 ULS performance.

Next parameter specifying the engine performance is the torque diagram as a function of the rotational speed. The Rotax 912 ULS engine achieves a nominal torque of $128 \mathrm{Nm}$ at a rotational speed of $5100 \mathrm{rpm}$. Above this speed, the torque value is already lower but still maintained above $120 \mathrm{Nm}$. The results obtained from the simulations indicate a similar maximum value of 126.96 $\mathrm{Nm}$, which is however attained at a higher speed of 5500 rpm. An analogous relationship occurs in the entire range from $3500 \mathrm{rpm}$ to $5800 \mathrm{rpm}$. Catalogue values are obtained in simulations at $500 \mathrm{rpm}$ higher speeds. For example, the torque value generated by the programme at $4000 \mathrm{rpm}$ is $114.61 \mathrm{Nm}$ while the actual value for $3500 \mathrm{rpm}$ equals $114.60 \mathrm{Nm}$. The exception is the first point where the torque value at $3000 \mathrm{rpm}$ is higher by $3.06 \mathrm{Nm}$, compared to the catalogue. No data from the manufacturer of the drive unit refers to values lower than $3000 \mathrm{rpm}$.

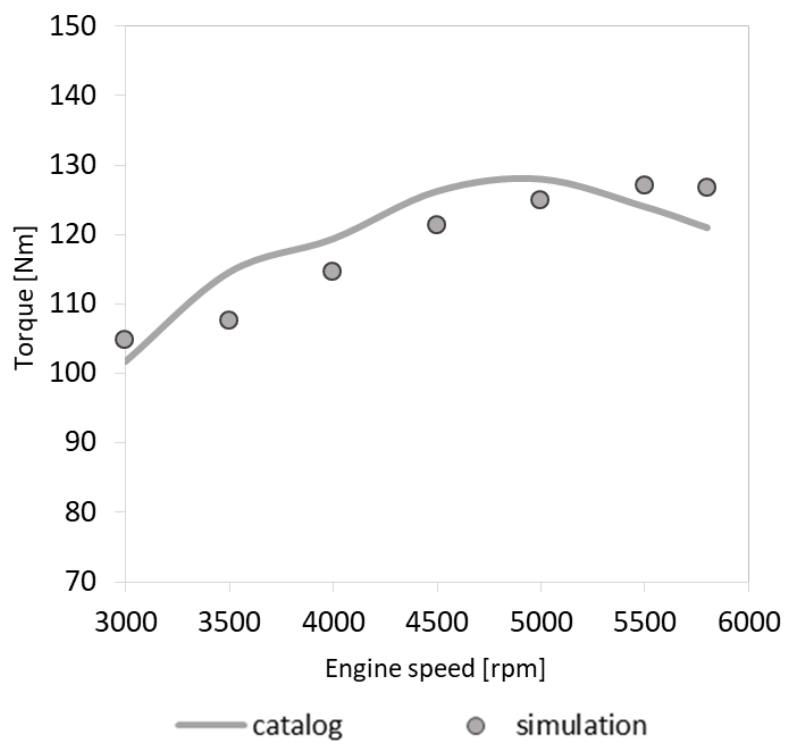

Fig. 8. Rotax 912 ULS torque.

The fuel demand of the drive unit is shown in the diagram (Fig. 9). The manufacturer's declaration in the catalogue lists fuel consumptions from $6.9 \mathrm{dm}^{3} / \mathrm{h}$ at 3000 $\mathrm{rpm}$ to $27 \mathrm{dm}^{3} / \mathrm{h}$ for a full-power engine with a rotational speed of up to $5800 \mathrm{rpm}$. The engine has cylinders cooled with flowing air and cylinder heads cooled with liquid. In order to lower the temperature inside the combustion chamber and thus the cylinders, the manufacturer recommends a rich air-fuel mixture. This means that the mixture supplied to the cylinders has less oxygen than needed to burn the fuel, and consequently full power at lower exhaust temperature can be achieved. The fuel consumption values obtained from the simulation of the computer model show an increased demand for fuel compared to the catalogue data in the range of $3000-3700 \mathrm{rpm}$. With the increase in the rotational speed, the dependence is reversed. However, one can observe an analogous relationship that occurred in the analysis of torque as a function of rotational speed. The fuel consumption values determined in the simulation correspond to the catalogue values obtained for speeds lower than $3000 \mathrm{rpm}$.

Referring to the simulation test results, it can be stated that the model still requires modifications. This will be possible after performing experimental tests which will provide additional data for further calibration 
of the model. The shift of the values on the torque characteristics, and thus the specific fuel consumption as a function of the rotational speed, may result from not including the full design of the drive unit in the model.

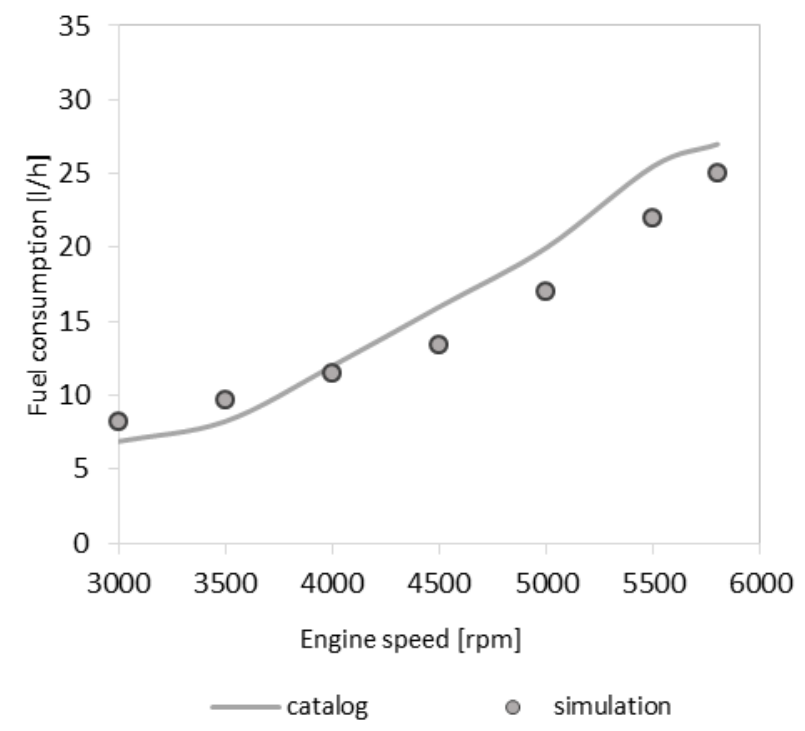

Fig. 9. Rotax 912 ULS fuel consumption.

The Rotax engine is an aviation structure and has the socalled dry-sump oil system. Engine oil is sucked out of the engine and is located outside the oil sump. In addition, the shaft design is modular and does not include arms with counterweights. Also, the motor is integrated with a reduction gear, an overload clutch and a hub that directly drives the propeller. Such a system significantly influences the mass distribution and mechanical resistance in the engine.

The values of air-fuel ratio (AFR) and the average effective pressure resulting from friction mean positive pressure (FMEP) influenced significantly the results of our calculations in the AVL Boost programme. Their more accurate calibration and simulation for more cycles would allow the model to be optimised and more in line with the results obtained experimentally. Further tests of the Rotax 912 ULS engine are carried out on the engine dynamometer set-up in order to determine the full characteristics of the moment power and the unit fuel consumption in the full speed range. The obtained results will allow us to complete the missing data in the programme and obtain a full calibration of the model. The model prepared in this way will be used for further research into engine development.

\section{References}

1. M. Wendeker, Z. Czyż, Maintenance and Reliability, 18 (1), 89-97 (2016)

2. Z. Czyż, P. Magryta, Maintenance and Reliability, 18 (4), 507-513 (2016)

3. M. Dopona, N. Foxhall, C. Dutzler, SAE Tech. Pap., 2012-32-0 (2012)

4. N. Wahla, D. Tither, P. Naude, Technovation, 18 (1998)
5. F. Nicolosi, A. De Marco, V. Sabetta, P. Della Vecchia, Aerosp. Sci. Technol., 76 (2018)

6. S. Gudmundsson, General Aviation Aircraft Design: Applied Methods and Procedures, (2014)

7. A.K. Sehra, W. Whitlow, Prog. Aerosp. Sci., 40 (2004)

8. J. Van Leersum, Appl. Numer. Math., 27, (1998)

9. D.P. Wells, Environ. Prot. (2011)

10. L. Grabowski, Z. Czyz, K. Kruszczynski, SAE Tech. Pap., 2014-01-28 (2014)

11. J. Shao, C. Rutland, J. Eng. Gas Turbines Power, 137, (2015)

12. J. Shao, C. Rutland, SAE Tech. Pap., 2014-01-12 (2014)

13. F. Magagnato, A. Walcker, M. Gabi, High Perform. Comput. Sci. Eng., 10 (2011)

14. M.H.W. Fadhli, A.L.A. Dali, S. Markus, S. Thomas, R. Ralf, W. Wolfgang, SAE Tech. Pap., 2007-240057 (2007)

15. L. Cornolti, A. Onorati, T. Cerri, G. Montenegro, F. Piscaglia, Appl. Energy, 111 (2013)

16. H.S. Kim, S. Oh, and J.Y. Choi, Aerosp. Sci. Technol., 69 (2017)

17. Y. Liu, F. Zhang, Z. Zhao, Y. Dong, F. Ma, S. Zhang, Appl. Therm. Eng., 104 (2016)

18. K. Pietrykowski, SAE Technical Paper 2014-012578, (2014)

19. V. De Bellis, E. Severi, S. Fontanesi, F. Bozza, Energy Procedia, 45 (2014)

20. V. De Bellis, R. Bontempo, Energy, 142 (2018)

21. T. Luigi, T. Daniela, B. Fabio, Energy Procedia, 126 (2017)

22. B. Shen et al., Energy Procedia, 142 (2017)

23. A.P. Carlucci, A. Ficarella, G. Trullo, Energy Convers. Manag., 122, (2016)

24. Ł. Grabowski, K. Pietrykowski, P. Karpiński, Book Series: ITM Web of Conferences, 15, 03002 (2017)

25. P. Magryta, K. Pietrykowski, M. Gęca, Transactions of the Institute of Aviation, 1-250, 3649 (2018)

26. G. D’Errico, T. Cerri, G. Pertusi, Appl. Energy, 88 (2011)

27. R. Sochaczewski, Z. Czyż, K. Siadkowska, Combustion Engines, 170 (2017)

28. Z. Czyż, Ł. Grabowski, K. Pietrykowski, J. Czarnigowski, M. Porzak, Journal of the International Measurement Confederation, 113 (2018)

29. K. Pietrykowski, T. Tulwin, SAE Int. J. Engines 8(1) (2015)

30. BRP-Rotax GmbH \& $\mathrm{CO} \mathrm{KG}$, Essential information regarding engine behavior, performance and manifold pressure data for ROTAX Engine Type 912 and 914 (Series) (2016) 